\title{
A inserção externa da indústria brasileira e catarinense entre 1994 e 2017
}

\author{
Hermano Caixeta Ibrahim* \\ Leonel Toshio Clemente**
}

\begin{abstract}
Resumo
$\mathrm{Na}$ tradição estruturalista latino-americana o desenvolvimento econômico deve ser fruto do avanço da estrutura produtiva e tecnológica dos países periféricos, permitindo melhoria da qualidade de vida de seus cidadãos. À luz da teoria estruturalista cepalina, o trabalho analisa a trajetória da indústria brasileira e catarinense a partir dos resultados do saldo comercial das manufaturas classificadas conforme seu coeficiente tecnológico nas décadas de 1990 e 2020 . O objetivo é apontar0 setores tecnológicos que apresentam alguma capacidade de concorrer pelo mercado mundial de produtos manufaturados. Os resultados apontam que, apesar do processo de desindustrialização da economia brasileira, o crescimento econômico no Brasil e no Estado de Santa Catarina foram acompanhados de uma melhoria na inserção internacional industrial até a primeira metade dos anos 2000, especialmente no setor de média intensidade tecnológica. Fora os momentos de recessão econômica, entre 2015 e 2017, os resultados dos saldos comerciais de manufaturas mostram um déficit crescente, nas mais intensas em tecnologia. Os resultados apontam que, apesar da dificuldade estrutural, alguns setores de média intensidade tecnológica se mostraram competitivos, em um período específico da história recente do país.
\end{abstract}

Palavras-chave: Estruturalismo; Crescimento; Desenvolvimento, Inserção externa.

\section{The international insertion of Brazilian and Santa Catarina industry between 1994 and 2017}

\begin{abstract}
In the Latin American structuralist tradition, economic development must be the result of advances in the productive and technological structure of peripheral countries, allowing improvement in the quality of life of their citizens. In the light of CEPAL's structuralist theory, the work analyzes the trajectory of Brazilian and Santa Catarina industry based on the results of the trade balance of manufactures classified according to their technological coefficient in the 1990s and 2020s. The results show that, despite in the process of deindustrialization of the Brazilian economy, the economic growth in Brazil and in the State of Santa Catarina was accompanied by an improvement in the industrial international insertion until the first half of the 2000s, especially in the sector of medium technological intensity. Apart from the moments of economic recession, between 2015 and 2017, the results of trade balances for manufactures show a growing deficit, in the more intense in technology. The results show that, despite the structural difficulty, some sectors of medium technological intensity proved to be competitive in a specific period in the country's recent history.
\end{abstract}

Keywords: Structuralism; Growth; Development, External Insertion.

Classificação JEL: O02; O04; L6

* Doutor em Economia do Desenvolvimento pela Universidade Federal do Rio Grande do Sul (UFRGS) e Professor Substituto da Universidade Federal do Piauí (UFPI). E-mail: hermanocaixeta@gmail.com

** Doutor em Economia do Desenvolvimento pela Universidade Federal do Rio Grande do Sul (UFRGS) e Professor efetivo da UFRGS E-mail: leonel_t_clemente@hotmail.com 


\section{Introdução}

A dificuldade de inserção internacional da indústria brasileira é tema recorrente do debate sobre ao processo de industrialização e sua contribuição para o desenvolvimento econômico. O avanço produtivo das economias periféricas sempre esteve atrelado as dificuldades de aprofundamento da industrialização, em virtude da incapacidade tecnológica industrial de competir nos mercados internacionais. Contudo, frente à queda dos custos logísticos e a ampliação das cadeias globais de valor, dinamizou-se e diversificou-se os setores e etapas produtivas disponíveis nessa moderna divisão internacional do trabalho. No caso do Brasil, mesmo frente a sua dificuldade histórica de competir nos mercados de produtos manufaturados, tivemos momentos na recente da economia brasileira em que alguns setores específicos se tornaram mais competitivos, e obtiveram melhores resultados nas exportações industrias. Nesse processo, a indústria catarinense repete tais restrições, porém de forma ainda mais acentuada.

Dessa forma, a partir da teoria estruturalista latino-americana o presente trabalho discute a inserção internacional da indústria brasileira e, em especial, do estado de Santa Catarina, a partir dos dados da balança comercial, produtividade e nível de utilização da capacidade para o período entre 1995 a 2015. Essa análise visa fomentar o debate em torno da política industrial e seu papel no desenvolvimento econômico, com base nos resultados históricos da indústria brasileira e catarinense, discriminando os setores industrias conforme suas capacidades tecnológicas e sua competitividade no mercado internacional.

O Gráfico 1 contextualiza o debate apresentando os dados da balança comercial da indústria brasileira, classificada conforme sua intensidade tecnológica (eixo esquerdo) e a trajetória do produto interno bruto (PIB) a preços constantes de 2015 (eixo direito) entre 1995 e 2020. Essas trajetórias mostram que, apesar do déficit estrutural nos setores mais tecnológicos, entre os anos de 2000 e 2006, o crescimento econômico foi acompanhado de uma melhoria nos saldos comerciais, especialmente nos setores de média intensidade tecnológica. Contudo, nos anos subsequentes, a continuidade do crescimento do PIB foi acompanhada da piora no saldo comercial em todos os setores, exceto nas manufaturas de baixa intensidade tecnológica. Tal déficit diminuiu apenas nos períodos caracterizados pela recessão econômica, entre os anos de 2015 e 2017. Esses dados remetem ao problema estrutural do processo de industrialização da economia brasileira no que tange a competitividade internacional nos setores industriais de maior coeficiente tecnológico. 
Gráfico 1 - Saldo comercial por coeficiente tecnológico e o PIB a preços constantes (2015) entre 1995 e 2020 (US\$).

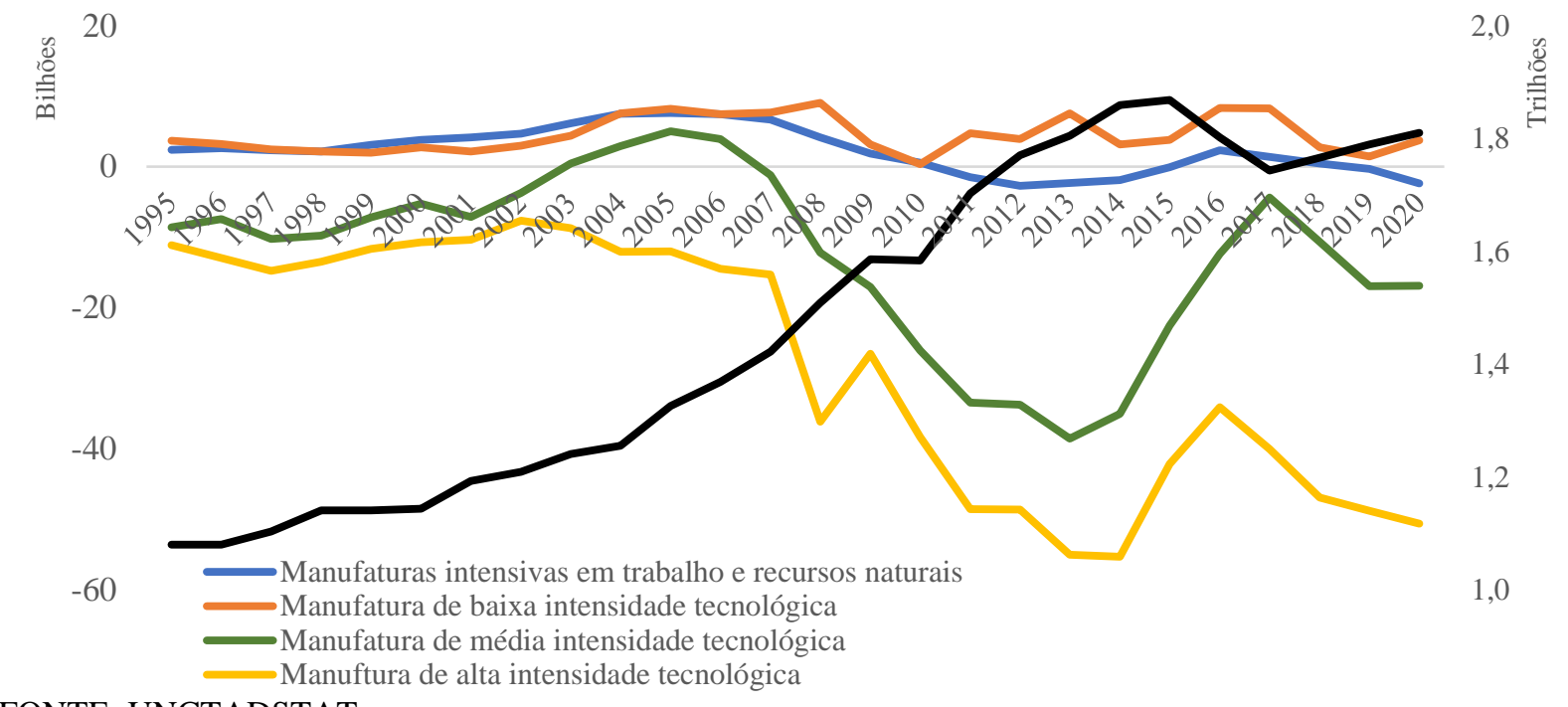

FONTE: UNCTADSTAT

Por sua vez, os dados da balança comercial (eixo da esquerda) e do PIB do estado de Santa Catarina (eixo da direita) ajudam a entender melhor a dinâmica do desenvolvimento econômico da indústria catarinense entre o período de 1997 e 2017. O crescimento entre 1997 e 2001 do produto interno bruto do estado foi acompanhado de uma relativa estabilidade da balança comercial em todos os setores industriais. A partir da recuperação do crescimento econômico entre 2003 e 2015, os setores intensivos em trabalho e recursos naturais, bem como os setores de média intensidade tecnológica, experimentaram uma melhora significativa na balança comercial. Contudo, apesar da manutenção do crescimento do PIB até 2015, a partir de 2005 verifica-se crescente deterioração da inserção internacional da indústria catarinense em todos os setores, em especial nas manufaturas de alta e média tecnologia.

Qualquer que seja a estratégia de desenvolvimento adotada, ela precisa ser realizada através de políticas econômicas, planejada e operacionalizada estrategicamente, e não apenas como forma de contornar ciclos econômicos. Nesse processo, a política industrial assume papel central na conformação das capacidades tecnológicas e produtivas da indústria nacional. Ela pode incentivar indústrias e setores específicos (e suas empresas) a alcançar os resultados, percebidos pelo Estado, como eficientes para a economia como um todo. Consideradas frutos do desejo de uma sociedade representada pelo Estado, a política industrial visa aprimorar o desenvolvimento industrial da nação. Dessa forma, o presente trabalho visa contribuir com a definição do atual estágio da industrialização da economia brasileira e catarinense, visando elencar os setores industriais que apresentaram melhor competitividade internacional no 
período recente, e que podem responder positivamente às políticas econômicas e às estratégias de desenvolvimento.

Gráfico 2 - Saldo comercial das manufaturas de acordo com a intensidade tecnológica (US\$) e a trajetória do PIB de Santa Catarina entre 1997 e 2017 (R \$ 2010)

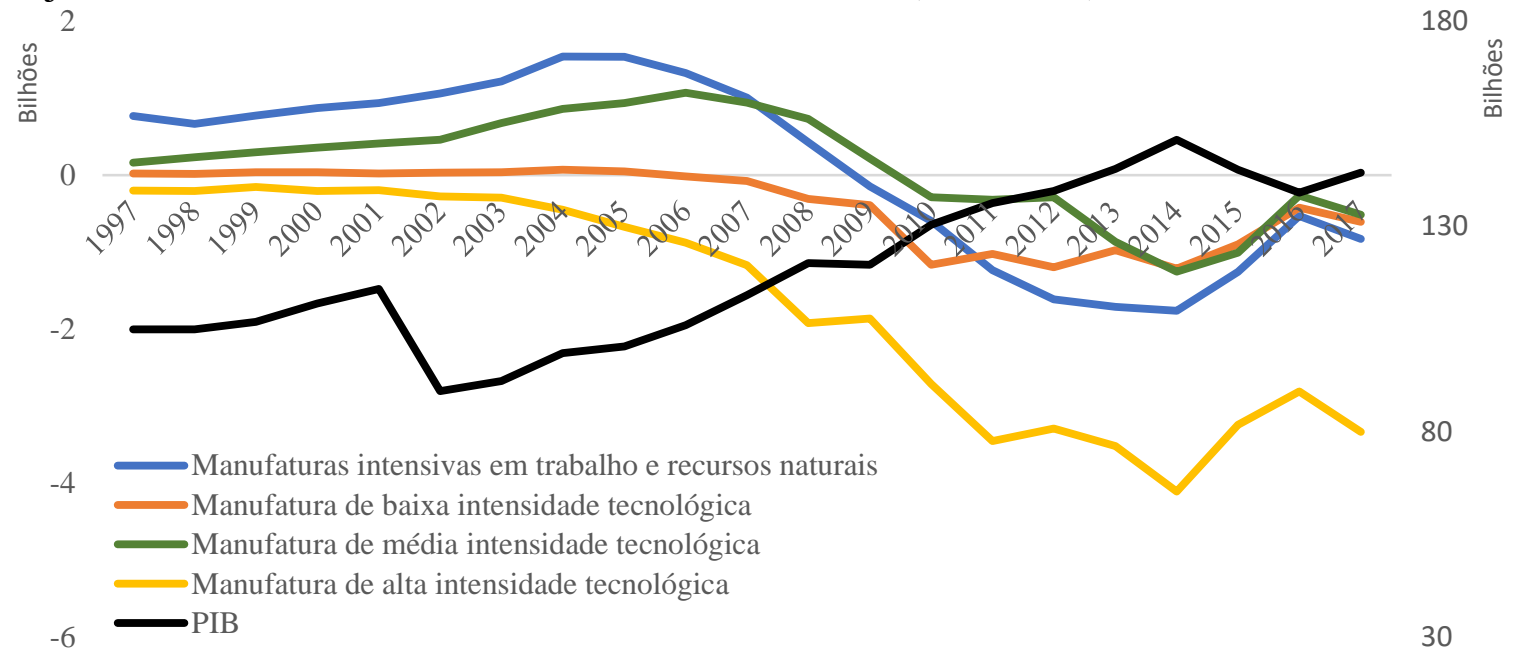

FONTE: IPEADATA E COMEX/STAT

Para tanto, o artigo encontra-se dividido em mais três seções além dessa introdução. Na seção seguinte resgata-se o debate estruturalista sobre a inserção externa industrial dos países latino-americanos e seu papel no processo de industrialização e desenvolvimento econômico. A terceira parte é dedicada ao debate teórico e empírico sobre a trajetória tecnológica da indústria brasileira na década de 1990 e 2000, seus números e correlações com o crescimento da produtividade e com o nível de utilização de capacidade, além de apresentar um recorte específico para o estado de Santa Catarina. Por fim, a conclusão traz o debate em torno da política industrial e seu papel no avanço da produtividade, dentro de uma estratégia de desenvolvimento econômico.

\section{O estruturalismo latino-americano e a inserção internacional das economias periféricas}

Dentre as correntes teóricas do pensamento econômico que se dedicam a analisar a estrutura produtiva e tecnológica, o estruturalismo cepalino se concentra em elencar os determinantes históricos e sociais que condicionam o crescimento econômico, e o processo de industrialização dos países latino-americanos. Esse pensamento propõe um método analítico específico para os problemas econômicos e sociais de países subdesenvolvidos: o históricoestruturalismo. 
Epistemologicamente, o estruturalismo busca compreender estruturas subjacentes, entendendo a existência de um conjunto de estruturas não observáveis, mas que ainda assim geram fenômenos sociais e econômicos reais. Metodologicamente, pode ser caracterizado como uma análise historicista de explicações descritivas, utilizando explicações dinâmicas da totalidade e das inter-relações do sistema. Dessa forma, essa escola de pensamento favorece as explicações sobre a forma como as estruturas causam, condicionam ou, assimetricamente, constituem aspectos econômicos da sociedade (BLANKENBURG, PALMA; TREGENNA, 2008).

Nesse referencial analítico, o desenvolvimento econômico significa o avanço das estruturas da produção dos bens e serviços, bem como, a evolução da ocupação da força de trabalho em um conjunto de mudanças concomitantes e compatíveis com a composição setorial e subsetorial dessas estruturas, dando curso à sua expansão e aprofundamento ordenado e contínuo. Analiticamente, o desenvolvimento é visto como resultado do cumprimento das condições de equilíbrio dinâmico, globais e setoriais, relativas tanto à produção, quanto à ocupação e distribuição, permitindo aos países subdesenvolvidos uma gradual superação da especialização e da heterogeneidade estrutural, melhorando o nível de renda médio e diminuindo a distância em relação aos países desenvolvidos (RODRIGUEZ, 2009).

Por essa leitura, o desenvolvimento econômico está relacionado com o aumento do bemestar material resultante do incremento da produtividade do trabalho. Já o aumento da produtividade dependente de métodos de produção, que incrementa a divisão técnica do trabalho e aumenta a dotação de capital por trabalho. Por sua vez, a maior densidade de capital é resultado da acumulação em torno do avanço tecnológico, preservando as margens de lucro e mantendo a continuidade do processo. Essa definição de desenvolvimento econômico remete em partes às teorias do crescimento de origem neoclássica e keynesiana, nas quais o processo de acumulação de capital está estreitamente ligado à elevação gradual da densidade de capital, ao aumento da produtividade do trabalho e ao progresso técnico.

O crescimento econômico guarda relação com a elevação gradual das capacidades tecnológicas, melhorando a produtividade do trabalho e permitindo ao país ter acesso ao mercado internacional. Todavia, além de elaborar uma teoria econômica própria aos países subdesenvolvidos, a Comissão Econômica para América Latina e Caribe (CEPAL) contribuiu com seu princípio "normativo" de atuação do Estado, via políticas econômicas para o ordenamento do desenvolvimento dos países latino-americanos. O planejamento não é visto como um substituto da economia de mercado, mas um meio para dar maior eficiência ao seu funcionamento às economias periféricas do sistema capitalista. Essa atuação é vista como 
imprescindível para que, de modo claro ou velado, consciente ou inconscientemente, possa promover os investimentos em determinados setores sem constranger a ação privada.

Com esse objetivo, a política industrial passou a ter a responsabilidade de promover competitividade, ao mesmo tempo em que vise reforçar padrões de especialização bem sucedidos e ajude a criar novos setores, estipulando metas e contrapartidas entre a iniciativa empresarial e o governo. Focada na formação de recursos humanos e no catching-up, a política industrial e tecnológica se tornam os instrumentos para a transformação produtiva frente às demais políticas econômicas. $\mathrm{O}$ foco da política se torna o incentivo à inovação no sentido mais amplo do termo, promovendo processos de aprendizagem associados às áreas de tecnologias, organização produtiva, estratégias de diversificação, desenvolvimento de complementaridades e ampliação da competitividade via avanço da infraestrutura, produção de insumos não comercializáveis e serviços especializados ( $\mathrm{P} \& \mathrm{D}$, logística e serviços de marketing).

Contudo, apesar da indústria permanecer como eixo central da transformação produtiva, o ambiente macroeconômico saudável é fundamental nas articulações tecnológicas e produtivas com as demais atividades: primária e de serviços. Para promover um crescimento econômico sustentável do ponto de vista do balanço de pagamentos, uma economia precisa manter a elasticidade-renda das importações à mesma taxa que a das exportações. Para manter equiparadas essas taxas, o setor produtivo nacional precisa acompanhar a demanda internacional em nível tecnológico e de escala, aliviando a restrição no balanço de pagamentos. Uma vez que o motor básico do crescimento econômico é a dinâmica inovativa, caberia à política industrial proporcionar as condições para elevação da produtividade e geração de competitividade industrial, possibilitando sua expansão para os demais setores e acesso à demanda internacional.

Na subseção a seguir, o trabalho resgata o debate estruturalista sobre o processo de industrialização e desenvolvimento econômico nos países da América Latina e a importância das capacidades tecnológicas industriais na conformação das características da inserção externa dessas economias. Para tanto, recorre-se aos primeiros trabalhos capalinos e aos conceitos da relação centro-periferia, deterioração dos termos de intercâmbio, a elasticidade renda das importações e exportações e o desequilíbrio estrutural na balança de pagamentos. Em seguida, destaca-se o papel colaborativo com a teoria estruturalistas dos trabalhos de Nicholas Kaldor na avaliação da importância do setor industrial exportador na manutenção do crescimento de econômico. 


\subsection{Processo de industrialização e inserção internacional da economia brasileira}

As atividades da Comissão Econômica para América Latina e Caribe (CEPAL) iniciamse em 07 de junho de 1948 em Santiago. A comissão nasce de uma iniciativa latino-americana em reação ao avanço do liberalismo econômico apregoado pelos EUA no pós-Segunda Guerra Mundial e perante as queixas de exclusão do Plano Marshall e do Plano Colombo. A partir da CEPAL, o pensamento estruturalista iniciou uma nova interpretação teórica para a peculiaridade do crescimento econômico nos países periféricos do sistema capitalista.

Em maio de 1949, Prebisch assumiu a Secretário Executivo da CEPAL, ocupando o cargo até 1963. Nesse período, a relevância política e acadêmica das ideias cepalinas ganhou destaque com a publicação dos primeiros estudos a respeito da polaridade centro-periferia na economia capitalista. $\mathrm{O}$ autor denunciou o funcionamento de um processo de desenvolvimento originalmente desigual na economia mundial, através da identificação de dois tipos de inserção no sistema de produção capitalista, um centro, hegemônico e industrial e uma periferia, dependente e agrária. Os países que não fazem parte do núcleo de economias capitalistas avançadas apresentam um setor primário-exportador incapaz de difundir o progresso técnico, aumentar a produtividade e permitir o crescimento sustentado dos salários reais. Como resultado, na periferia a estrutura produtiva se mantém especializada e heterogênea ${ }^{1}$, enquanto que nas economias centrais é diversificada e homogênea ${ }^{2}$.

O diagnóstico apontado explicita que os preços dos produtos primários - usualmente exportados pelos países latino-americanos - tenderiam a cair em relação aos industrializados, fazendo com que as quantidades exportadas de bens primários tivessem que crescer constantemente para suprir as necessidades de bens industriais nos países periféricos. O livre comércio e a especialização produtiva levavam a uma deterioração dos termos de troca entre os países periféricos, agrícolas e atrasados, com os do centro, industrializados e desenvolvidos. Dessa forma, Prebisch (1949, p. 119) questionou, particularmente, a Teoria das Vantagens Comparativas desenvolvida pelo economista David Ricardo, e propagada pela Escola Liberal Clássica, através do modelo de Heckscher-Ohlin. Se a demanda por produtos primários e as exportações crescessem suficientemente não seria necessário pensar em restrições, porém “as

\footnotetext{
${ }^{1}$ Nos países periféricos, novas técnicas só são implantadas nos setores exportadores de produtos primários e em algumas atividades econômicas diretamente relacionadas com a exportação, as quais passam a coexistir com setores atrasados (MISSIO; JAYME JR; OREIRO, 2015).

${ }^{2} \mathrm{O}$ caráter especializado e unilateralmente desenvolvido é resultado dos recursos produtivos serem destinados exclusivamente para ampliações do setor exportador de produtos primários, enquanto a demanda de bens e serviços, que aumenta e se diversifica, é satisfeita por meio de importações.
} 
exportações da América Latina dependem das variações da renda dos Estados Unidos e da Europa, principalmente e de suas respectivas quotas de importação de produtos latinoamericanos.”. Na concepção básica do sistema centro-periferia, a industrialização é sinal de mudança no padrão de crescimento do polo periférico: do desenvolvimento denominado "para fora" baseado na expansão das exportações, para o desenvolvimento "para dentro" ancorado na ampliação da produção industrial (RODRIGUEZ, 2009).

Desde seus primeiros trabalhos, o estruturalismo cepalino sempre destacou a importância da industrialização para a superação da condição periférica e do subdesenvolvimento. Sobre esse mesmo tema, Nicholas Kaldor em 1966 apresentou uma abordagem setorial para compreender o lento crescimento econômico britânico no pós-guerra. Nesse trabalho, o autor concluiu que a indústria é o único setor que tem capacidade de impulsionar o crescimento dos demais setores da economia, devido ao efeito de encadeamento causado ao demandar recursos de outros setores e ao promover ganhos de escala e crescimento do produto, do emprego e da produtividade. Segundo Lamonica e Feijó (2011, p.121), Nicholas Kaldor:

"[...] identifica a indústria como o "motor do crescimento" por ser o setor mais dinâmico e difusor de inovações. As intra e inter-relações da indústria com os demais setores induzem a um aumento na produtividade dentro e fora dela. Como os retornos crescentes estão presentes na indústria, as mudanças nos processos de produção se propagam continuamente, ou seja, de um modo cumulativo".

A partir de estudos econométricos, Kaldor (1966) encontrou que a taxa de crescimento do produto agregado e a taxa de crescimento do setor industrial apresentam uma correlação positiva, não devido à grande participação do produto industrial no PIB total, mas pelo crescimento da produtividade dentro e fora de tal setor. A produtividade do trabalho se mostrou intrinsicamente relacionada com o crescimento da produção industrial, de forma que, quando a produção industrial cresce, ocorrem relevantes transformações na estrutura produtiva e na composição da demanda, induzindo tanto novos processos mais produtivos, como novos produtos e mercados. Dessa forma, o crescimento da produtividade é um fenômeno macroeconômico, fruto do crescimento da demanda e das possibilidades de economias de escala dinâmicas presentes, principalmente no setor manufatureiro. Quanto maior a taxa de crescimento da indústria, maior será também a taxa de crescimento da produtividade. Todavia, esse crescimento é desigual entre os diversos setores, uma vez que nos setores crescentes em escala apresentarão maior crescimento e maior dinamismo em sua evolução, conforme a demanda agregada se expande. 
Em um primeiro momento, apenas a demanda interna era considerada como fonte de incentivo ao aumento de produtividade, porém, ao tratar do ritmo de crescimento de longo prazo, incluindo a demanda externa, as exportações passam a ser a principal fonte de expansão da demanda agregada. Segundo o Kaldor (1966), elas são capazes de elevar a taxa de crescimento da renda através do multiplicador de comércio exterior, e de relaxar a restrição imposta pela condição de equilíbrio no balanço de pagamentos, permitindo que os demais componentes da demanda também se expandam. Dessa forma, quanto maior for taxa de crescimento das exportações industrias, maior seria o crescimento do produto.

Uma vez que as restrições externas podem inibir o crescimento, as exportações precisam crescer, no mínimo, ao mesmo ritmo das importações. Dessa forma, o crescimento no longo prazo depende da capacidade de um país manter a competitividade de suas exportações através elevação da produtividade na indústria de transformação. Thirlwall (1980) formalizaria essa restrição, encontrando que a taxa de crescimento da produtividade da indústria e a taxa de crescimento do PIB no longo prazo são determinadas pela taxa de crescimento das exportações, em relação à elasticidade-renda de demanda por importações.

Para manter um crescimento sem restrição no balanço de pagamentos, uma economia precisaria manter a elasticidade-renda das importações à mesma taxa que a das exportações. Contudo, para manter equiparadas essas taxas, o setor produtivo nacional precisa acompanhar a demanda internacional em nível tecnológico e de escala, aliviando a restrição no balanço de pagamentos. Uma vez que o motor básico do crescimento econômico é a dinâmica inovativa, caberia à política industrial proporcionar as condições para elevação da produtividade e geração de competitividade industrial, possibilitando sua expansão para os demais setores e acesso à demanda internacional.

\section{A inserção da indústria brasileira no século $X X$}

Os avanços dos preceitos da ortodoxia convencional através do Consenso de Washington para os países da América Latina, desde 1989, reforçaram a necessidade da CEPAL realizar sua autocrítica. O documento 'Transformación productiva com equidad - TPE' (CEPAL, 1990) inaugura as premissas básicas do neoestruturalismo e da nova retórica cepalina. O documento faz um resumo das experiências dos países latino-americanos na década de 1980, e denuncia os problemas do balanço de pagamentos deficitário e a desorganização das contas públicas. 
No início da década de 1990, as políticas econômicas nos países da América Latina passam a seguir, majoritariamente, as ideias liberais de fortalecimento do papel dos mercados na alocação de recursos e na redução do tamanho e das atribuições do Estado, incluindo a privatização de empresas e serviços públicos, maior liberalização de movimentação para o capital e para o comércio exterior e o favorecimento do investimento direto externo (IDE). A interpretação foi de que os fluxos de capital "globalizados" são mais importantes do que qualquer outra dimensão da política econômica. A taxa de retorno dos capitais era fundamental nos esforços para o controle da inflação, através do uso da taxa de câmbio como referencial para os movimentos dos preços internos. Ao estabelecer "âncoras cambiais" como base das políticas de estabilização, os governos permitiram a reavaliação da taxa de câmbio e o refinanciamento dos déficits em conta corrente, em um contexto de rápida liberalização unilateral do comércio. Ademais, o ingresso de capitais conteve a expectativas inflacionárias frente uma maior competitividade interna. A convergência com as diretrizes do 'Consenso de Washington' resultou no retorno do ingresso de capitais, majoritariamente para financiamento das dívidas estatais e privatizações.

A esperança era de que, feito o ajuste recessivo defendido pelo Fundo Monetário Internacional (FMI) e pelos credores da dívida, logo os países da América Latina retomariam a confiança do mercado internacional e voltariam a crescer baseado na atração de investimento. Todavia, a CEPAL (1985) aventou a ideia de políticas de ajuste expansivo, sem submeter os países periféricos ao ajuste recessivo da balança de pagamentos. Nessa visão, o desequilíbrio externo deveria ser resolvido com crescimento econômico, dinamização dos investimentos em setores de bens comercializáveis, especialmente ao crescimento e diversificação das exportações. Para o neoestruturalismo havia lacunas, falhas e distorções no processo de industrialização periférico, as quais precisariam ser reformadas em direção do crescimento com criatividade, necessário para inserir e manter as economias no mercado mundial (BIELSCHOWSKY, 2000).

Em um primeiro momento, o foco do neoestruturalismo foi a dinâmica da inovação e do progresso tecnológico e seu impacto na manutenção do subdesenvolvimento periférico. Nessa leitura, o progresso técnico é entendido como um aumento dos conhecimentos sobre o que e como produzir. Todavia, o avanço tecnológico só se materializa pela via das inovações introduzidas nos processos produtivos ou mercados. Ademais, para serem efetivas, as inovações precisam se incorporar aos investimentos em bens de capital, acumulando o conhecimento e aumentando sua disponibilidade necessária para o crescimento da produção, globalmente considerada. No que tange os aspectos econômicos, as estratégias de desenvolvimento sob esse 
novo enfoque teórico, associa o crescimento à dinâmica do progresso técnico, acumulação de capital e crescimento do produto, aumentando a produtividade do trabalho e conformando padrões distributivos que possibilitem a demanda de bens e serviços, compatíveis com a expansão da produção. Apesar de atribuir ao mercado interno parte da dinâmica produtiva, o mesmo passa a ter importância secundária, não sendo inserido na lógica da argumentação da década de 1990.

A mudança de foco se deve principalmente à inserção da teoria neoschumpeteriana, seus conceitos e propostas analíticas sobre o processo de inovação, no entendimento sobre o processo de subdesenvolvimento. Por essa visão, a inovação em processos e produtos originase no interior da empresa. A capacidade de inovar não está separada da organização ou gestão, pois se origina na execução reiterada dos processos produtivos, de tal modo que a inovação é um resultado indissociável da relação entre empregados, empregadores e a tecnologia vigente. Ao trazer para o debate estruturalista os conceitos neoschumpeterianos sobre o processo de inovação, desenvolvimento, rotina, busca, seleção, conhecimento, aprendizagem, paradigmas e trajetórias tecnológicas, a CEPAL incorporou os novos avanços científicos à análise do subdesenvolvimento.

Tanto a história como as teorias econômicas reconhecem a importância da relação entre as mudanças tecnológicas e o crescimento e desenvolvimento econômico. A contribuição teórica sobre a questão tecnológica da ciência evolucionária schumpeteriana permitiu ao estruturalismo cepalino, desenvolver abordagens microeconômicas para analisar o processo de cathing-up tecnológico dos países periféricos. A aprendizagem tecnológica é definida por Cimoli e Porcile (2011) como um conjunto de regularidades inter-relacionadas sumarizadas em cinco pontos: existem complementariedades entre setores e as capacidades tecnológicas, de forma que as externalidades e o aumento dos retornos são cruciais para níveis industriais e macroeconômicos; aprendizagem tecnológica requer tempo; está sujeita ao processo de path dependency, ou seja, a evolução das capacidades dependem das experiências e direções passadas; existem irreversibilidades (física e tecnológica) de alguns ativos, além de apresentar altos custos de abandono; e por fim, possui um componente crítico que não pode ser obtido com a importação de bens de capital nem com a leitura de manuais e outras formas de informação codificada.

O pensamento evolucionário neoschumpeteriano enfatiza o papel da mudança tecnológica na formação das capacidades tecnológicas e no crescimento econômico (DOSI, 1988, 2008; PEREZ, 1992, 2004, 2010). As economias que apresentam sistemas nacionais de inovação desenvolvidos, capazes de produzir e absorver novos paradigmas tecnológicos 
transformando sua estrutura de produção, aumentando a participação de setores intensivos em $\mathrm{P} \& \mathrm{D}$, conseguirá convergir para a produtividade dos países da fronteira tecnológica, realizando assim, o processo de catching-up tecnológico e produtivo. Por sua vez, a característica da inserção nos paradigmas tecnológica depende da cumulação de capacidades tecnológicas (CTs) relacionada à transformação e diversificação da estrutura econômica.

Assim, o desenvolvimento econômico se caracteriza pelo processo pelo qual um país transforma suas estruturas produtivas e de emprego baseadas, na aprendizagem e na inovação, acumulando capacidades tecnológicas (CTs) e suas complementariedades (CIMOLI; POCILE, 2011, 2013, 2014). O estruturalismo cepalino explica a macrodinâmica tecnológica e a especialização produtiva no crescimento econômico, relativo entre as economias centrais e periféricas. O micro schumpeteriano se relaciona com a macro estruturalista, através dos processos de aprendizagem e acumulação de capacitações tecnológicas (CTs). Diferentemente da função de produção agregada no sentido neoclássico tradicional, o crescimento da produtividade é determinado por Ocampo (2005) através: do conjunto de oportunidades associado à posição na hierarquia internacional e capacidades adquiridas de produção e tecnológicas; da reação dos empresários a essas oportunidades; dos incentivos que as empresas enfrentam na competição; e da qualidade das instituições redistributivas.

Dessa forma, no que tange a questão industrial e tecnológica nos países periféricos, o início da década de 1990 foi marcado pela abertura comercial, eliminação do protecionismo existente nas décadas anteriores, fim das barreiras não-tarifárias e redução das alíquotas de importação. Em meio a esse processo de abertura para a concorrência internacional, as orientações de políticas econômicas não se preocuparam em propor uma política industrial que definisse uma estratégia de engate do país nas cadeias de valor, considerando setores mais dinâmicos ou capacidades de encadeamentos internos. $\mathrm{O}$ resultado da abertura foi uma relativa melhora da produtividade, porém, com perda de encadeamentos produtivos e uma reespecialização regressiva da estrutura produtiva.

Nos anos subsequentes, a paridade cambial instituída pelo plano Real, valorizando a moeda nocional, juntamente com a abertura comercial às importações e a retirada de incentivos fiscais às indústrias nacionais, reconfigurariam drasticamente o setor produtivo brasileiro e sua respectiva inserção no mercado externo. A abertura financeira e comercial incentivou a especialização reversa do parque produtivo à medida que a importação de maquinas, equipamentos, peças, insumos e matéria-prima ficaram acessíveis, desarticulando a cadeia de fornecedores nacionais e forçando-as a se especializar em atividades de comércio. Esse comportamento foi verificado com mais intensidade na indústria intensiva em tecnologia e 
capital. Na indústria intensiva em mão de obra e recursos naturais houve um aumento na inserção internacional à medida que o processo de abertura e valorização cambial permitia acesso a variados mercados.

Ocampo (2005) explica que a liberalização desencadeia uma "inovação" por permitir às empresas ter melhor acesso aos insumos e bens de capital importados. No entanto, a destruição de ligações internas e capacidades tecnológicas anteriores, devido à especialização em atividades com economias de escala dinâmicas mais fracas, tendem a comprometer a expansão da produtividade. Embora os efeitos microeconômicos da competição sobre o crescimento da produtividade possam ser positivos, a especialização pode ter efeitos macroeconômicos negativos. Sendo assim, as economias periféricas precisam alcançar as taxas de mudança estrutural que são necessárias para preencher gradualmente a brecha que a separa do mundo industrializado.

Basicamente, a abertura comercial não foi tão benéfica para aqueles setores os quais já conseguiam competir no mercado internacional, e prejudicou a indústria nacional no sentido de concorrência com produtos estrangeiros. Por outro lado, foi um choque de realidade para o parque produtivo, forçando-o a se aperfeiçoar perante a nova realidade competitiva. Os esforços de investimento em $\mathrm{P} \& \mathrm{D}$, modernização e novos produtos foram transferidos para o aprimoramento da capacidade produtiva e para o desenvolvimento de processos mais eficientes. Nesse interim, as alianças estratégicas ganharam notoriedade, uma vez que diluíam os custos e riscos de novos empreendimentos.

Segundo Cimoli e Pocile (2011), a liberalização do comércio e a valorização da moeda local favoreceram os setores menos intensivos em tecnologia. Um efeito semelhante está relacionado com choques positivos nos termos de troca das exportações de commodities, à medida que os recursos foram realocados para outras atividades menos intensivas em tecnologia. A mercantilização da produção durante a industrialização periférica guiada pelo Estado, fez com que investimento em $\mathrm{P} \& \mathrm{D}$ e em infraestruturas perdessem prioridade nas firmas. Houve menor demanda de adaptação às condições locais e menor interação entre produtores e usuários. Por outro lado, a liberalização tornou as empresas mais próximas às cadeias globais de valor, em que o estímulo à aprendizagem local foi sendo abandonada em favor de um foco na homogeneização de insumos e bens, dentro de um sistema hierárquico de produção. Isso ocorreu em paralelo com a "comoditização" progressiva da produção de bens e serviços na região. Esses processos resultaram em uma desarticulação das cadeias produtivas locais, juntamente com a marginalização de pequenas e médias empresas nacionais. A racionalização baseada no uso mais intenso de insumos e equipamentos importados produziu 
gaps na matriz de produção, e efeitos negativos nos níveis de emprego e heterogeneidade estrutural.

Outro fator importante, principalmente durante os anos 2000, é o processo de apreciação do câmbio e seu impacto sobre o salário real e sobre os custos de produção em relação ao resto do mundo. Esse processo induz a migração de atividades produtivas, antes realizadas na economia doméstica, para o exterior, causando uma desindustrialização da economia doméstica, afetando a capacidade exportadora do país e as elasticidades-renda das importações e exportações no longo prazo. A dificuldade de manter o aumento da produtividade, via processo de industrialização nos países que passaram pelo processo de substituição de importação reside em duas características segundo Bresser-Pereira (2016): no atraso tecnológico e na baixa competitividade frente ao mercado internacional de bens manufaturados e; nos efeitos da "doença holandesa", provocando desindustrialização do tecido produtivo e reprimarização da pauta exportadora. O resultado da desindustrialização é o aumento dos déficits comerciais com elevação dos superávits no setor não industrial. Uma economia se desindustrializa quando o setor industrial perde importância como fonte geradora de empregos e/ou de valor adicionado numa certa economia; e não quando a produção industrial está estagnada ou em queda. O conceito de "desindustrialização" é compatível com o aumento físico da produção industrial, a simples expansão de atividades manufatureiras (quantidade) não invalida a ocorrência do processo de desindustrialização (OREIRO; FEIJÓ, 2010).

Pereira e Cario (2017) relembram que na interpretação estruturalista o processo de desindustrialização das economias periféricas a partir da década de 1990 foi marcado pela rápida e ampla abertura econômica, recuo do papel do Estado na organização e incentivos ao setor e perda da capacidade de investimento em infraestrutura e em pesquisa e desenvolvimento. Ademais, para os autores $(2017$, p.14) “a dimensão histórica e a importância das decisões de estratégia de desenvolvimento é um elemento importante para entender a quadro de desindustrialização atual e as possibilidades de sua superação". Dessa forma, as características da política industrial ao longo dos anos 1990 e 2000 reacendem o debate sobre a forma como o Estado pode atuar para o desenvolvimento e suas limitações no processo de coordenação. Segundo Pereira e Cario (2017, p14), “elementos nem sempre quantificáveis e passiveis de ação deliberada da política econômica, porém que, na maioria das vezes, exerce papel central no sucesso ou fracasso na promoção da industrialização e desenvolvimento.”.

Para Cimoli e Porcille (2011) a competitividade baseada em atividade intensiva em trabalho e em recursos naturais não é sustentável ao longo do tempo. É a competição por capacidades tecnológicas (CTs), que permite à periferia estar presente nos mercados onde a 
demanda cresce em taxas maiores. À medida que aumenta a participação dos mais setores intensivos em tecnologia, aumentam os retornos e as externalidades que promovem o crescimento das exportações, da acumulação de capitel e do crescimento. No caso da América Latina, segundo Cimoli e Porcile (2011), a acumulação de capacidades tecnológicas foi profundamente afetada pela macroeconomia, através dos choques estruturais e por fracas instituições de ciência e tecnologia. Segundo os autores, as estruturas econômicas da América Latina são o resultado da rápida liberalização do comércio, da apreciação da moeda nacional e de grandes fluxos de capital estrangeiro, bem como a ausência de políticas industriais e tecnológicas ativas, impactando nas estratégias competitivas das firmas.

O Gráfico 3 ilustra bem o problema de desindustrialização da economia brasileira ao longo das décadas de 1990, 2000 e 2010. Nele tem-se no eixo da esquerda a participação das manufaturas como percentual do PIB, no eixo da direita é plotado novamente a trajetória dos diferentes setores industriais separadas pela sua intensidade tecnológica. Após chegar a mais de 30\% de participação da indústria no PIB, esse setor da economia entra a década de 1990 já próximo da metade da participação da década anterior. Não obstante, na segunda metade da década de 1990, a indústria continuou a perder importância na dinâmica econômica do país, chegando a representar apenas 14\% do PIB em 1998. Apesar da continua queda, o perfil da inserção internacional pouco mudou nos primeiros anos da série, contudo, a partir de 1999, os setores de média intensidade tecnológica passam a melhorar sua balançar comercial acompanhando a retomada do crescimento da participação da indústria.

Por sua vez, esse crescimento durou até 2006, quando a participação da indústria volta a cair, juntamente com a piora no saldo comercial em quase todos os setores, com exceção dos setores de baixa intensidade tecnológica que mantém um superávit relativamente constante. $\mathrm{O}$ destaque fica para os 10 últimos anos da série em que o país experimentou uma abrupta desindustrialização, perdendo mais de 5\% de participação do PIB entre 2008 e 2014. Por fim, a diminuição do déficit comercial nos setores de média e alta tecnologia entre 2014 e 2017 guardou maior relação com a desaceleração da economia e com a recessão econômica em 2015 e 2016. Nos últimos anos da série, o déficit estrutural em setores de maior coeficiente tecnológico voltou a aumentar e é acompanhado de um aprofundamento da desindustrialização, chegando em 2019 com a indústria correspondendo apenas a 11\% do PIB. 
Gráfico 3 - Participação da indústria no PIB (\%) e o saldo comercial do setor manufatureiro conforme intensidade tecnológica entre 1995 a 2019 (US\$)

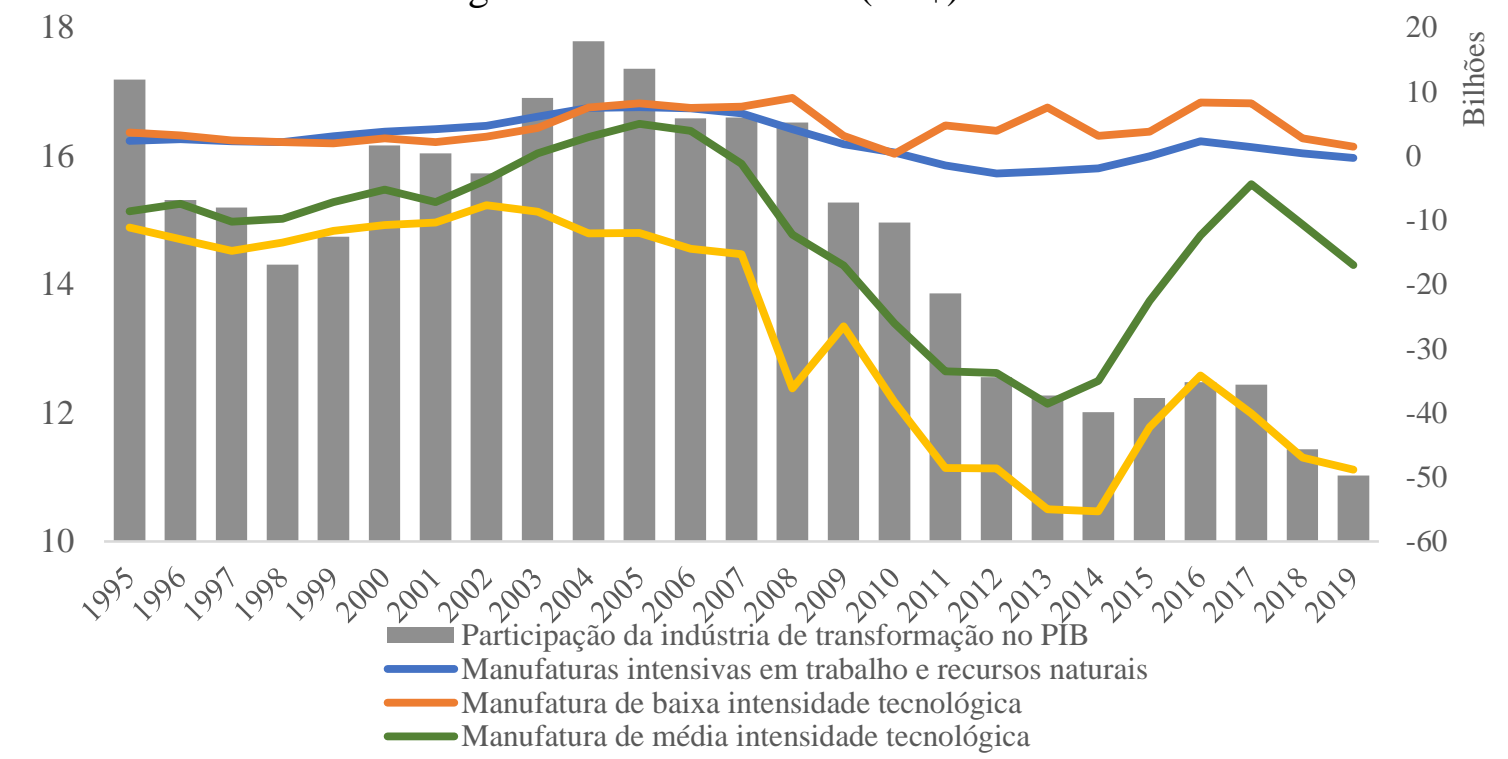

FONTE: UNCTAD-STAT

Os dados sobre o perfil de inserção externa da indústria brasileira nos últimos 25 anos, além de evidenciar os problemas estruturais das economias periféricas, permitem vislumbrar quais setores tecnológicos apresentaram melhor capacidade de concorrer pelo mercado internacional. Uma vez que a proposta de análise estruturalista visa também contribuir com a orientação do processo de industrialização e desenvolvimento econômico, vale analisar mais de perto a relação entre o aumento da participação da indústria no PIB, sua contribuição com o aumento da produtividade e a melhoria na balança comercial das manufaturas de média e baixa tecnologia

Sobre esse tema, Ibrahim (2019) desenvolveu um modelo vetorial de correção de erros (VEC) que relaciona o crescimento do PIB com a produtividade total dos fatores e o saldo comercial por grupo de manufaturas, divididas conforme o seu componente tecnológico (recursos naturais e mão de obra, baixa, média e alta tecnologia). Esse modelo utilizou os dados anuais em painel de nove economias subdesenvolvidas latino-americanas (Argentina, Bolívia, Brasil, Chile, Colômbia, Equador, México, Peru, Paraguai, Uruguai e Venezuela) para avaliar as relações entre a estrutura produtiva e tecnológica e o crescimento econômico. A relação entre as variáveis foi estimada e comparada a partir dos modelos de vetores autorregressivos (VAR).

O trabalho conclui que, durante o período entre 1994 a 2014, a produtividade total dos fatores esteve relacionada negativamente com o crescimento do PIB, uma vez que, apesar do crescimento ter acelerado na segunda década, a produtividade apresentou uma trajetória geral de queda. No que tange ao saldo comercial das manufaturas classificadas conforme o seu componente tecnológico, tanto as manufaturas intensivas em recursos naturais e mão de obra, 
como as de alta e baixa tecnologia, apresentaram relação de cointegração negativa com o crescimento do PIB. Já o saldo comercial das manufaturas de média tecnologia foi o único setor que apresentou cointegração positiva com o crescimento do PIB e utilização de capacidade.

Figura 1 - Resposta do crescimento à variação nos grupos de manufaturas classificados conforme componente tecnológico (recursos naturais, baixa, média e alta tecnologia) para o grupo de países selecionados

Response to Cholesky One S.D. Innovations
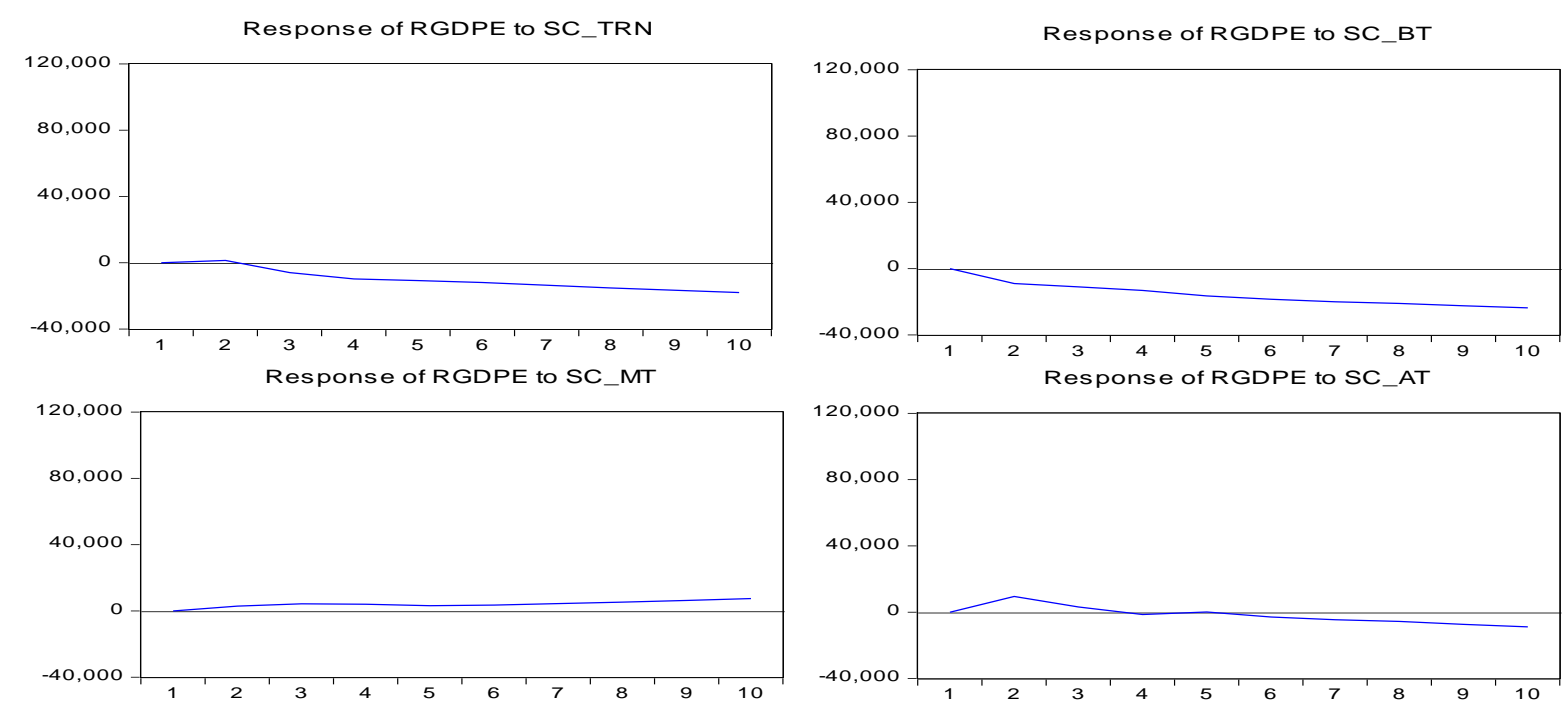

FONTE: IBRAHIM (2019).

A partir de funções de impulso e resposta, o trabalho simula o impacto do saldo comercial das manufaturas, classificadas pelo seu componente tecnológico, no crescimento do PIB e na produtividade conforme apresentado na Figura 1. O resultado foi que choques no saldo comercial das manufaturas intensivas em recursos naturais e mão de obra e das manufaturas de baixa tecnologia impactaram negativamente o crescimento do PIB. Os choques no saldo comercial dos setores de média intensidade tecnológica foram acompanhados de uma resposta positiva do produto. Por fim, apesar de responder positivamente no curto prazo a choques no saldo comercial das manufaturas de alta tecnologia, os impactos dos choques foram revertidos ao longo da série analisada.

Por sua vez, a Figura 2 apresenta as respostas da produtividade às variações na utilização de capacidade e no saldo comercial das manufaturas classificadas pelo componente tecnológico para o grupo de países selecionados. Na série analisada, os choques na utilização de capacidade foram respondidos por uma melhoria da produtividade. Por sua vez, a produtividade também respondeu positivamente à choques saldos comerciais das manufaturas de baixa, média e alta tecnologia. 
Figura 2 - Resposta da produtividade às variações na utilização de capacidade e no saldo comercial das manufaturas classificadas pelo componente tecnológico (recursos naturais, baixa, média e alta tecnologia) para o grupo de países selecionados

Response to Cholesky One S.D. Innovations

Response of CWTFP to UTIL

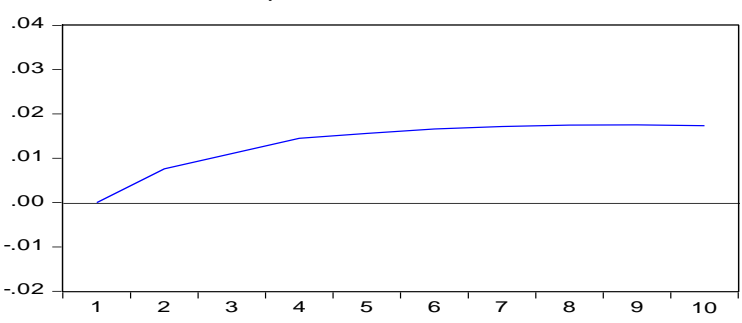

Response of CWTFP to SC_TRN
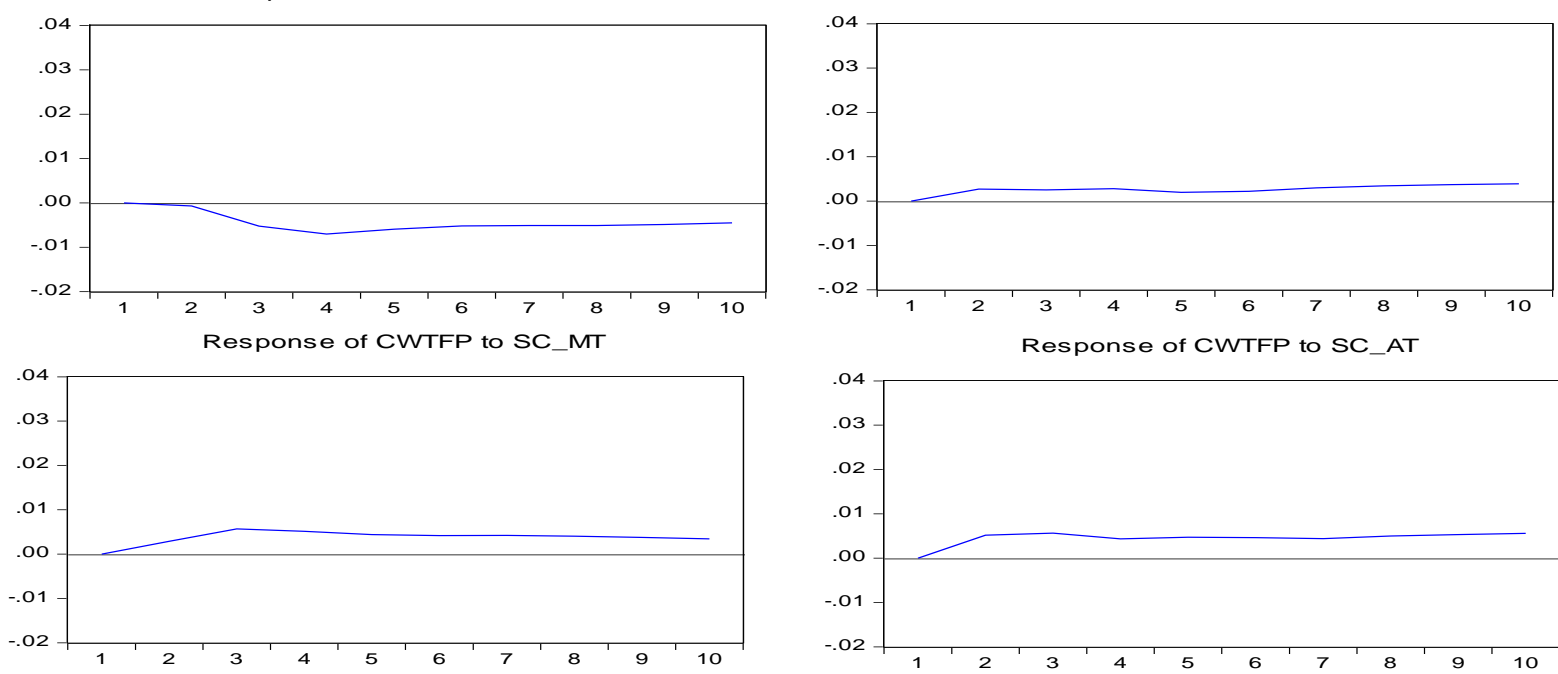

FONTE: IBRAHIM (2019)

A partir desses resultados é possível inferir que o setor de média intensidade tecnológica apresenta o melhor potencial de respostas às políticas econômicas, seja pelos seus impactos na produtividade, seja pelo impacto direto no crescimento do PIB. Contudo, vale destacar, também, a relação da estrutura produtiva e tecnológica da indústria brasileira com a taxa de câmbio efetiva real do Brasil. A literatura estruturalista sempre se preocupou com a operacionalização dessa variável macroeconômica, seja devido aos seus impactos nas elasticidades rendas da demanda por exportações e importações, seja por sua relação com a distribuição de renda, investimento e avanço da estrutura produtiva e tecnológica.

Recentemente, vários estudos se propõem a avaliar a relação entre a taxa de câmbio real e o processo de mudança estrutural no setor industrial. Marconi e Rocha (2012) concluem que as taxas de câmbio reais, entre 1995 e 2008, contribuíram para a desindustrialização brasileira. Utilizando uma base de dados setorial para o período 1996-2012, Araújo e Peres (2018) mostram que os períodos com câmbio real valorizado alteraram a estrutura produtiva brasileira em favor das atividades primárias, em detrimento do setor tecnologicamente mais avançado. Por fim, Ribeiro, McCombie e Lima (2019) relembram que operacionalização da política 
cambial através da taxa real de câmbio ao mesmo tempo em que pode promover a mudanças na melhoria do crescimento da estrutura produtiva da economia, estimulando o progresso tecnológico e os spillovers de conhecimento e afetando positivamente o crescimento do produto; pode também ser responsável pelo aumento da desigualdade de renda, reduzindo os salários reais e, portanto, prejudica o consumo agregado e o crescimento do produto.

No trabalho de Ibrahim (2019), são apresentados os dados de comércio internacional específicos do setor de média intensidade tecnológica, o qual experimentou um período de relativa melhora na balança comercial, eixo da esquerda, junto com a taxa de câmbio efetiva real no Brasil entre 1995 e 2015. Dentre as atividades que compõe o grupo, as com maior relevância na balança comercial do setor foram aquelas relacionadas à indústria automotiva. $\mathrm{O}$ período entre 1999 e 2006 foi marcado pela melhora da balança comercial, especialmente a partir de 2002, com a melhoria do saldo comercial dos setores de motores para veículos de transporte de mercadorias (caminhões e utilitários), fabricação de papel, maquinas de trabalho do metal e engenharia civil. Entretanto, a contínua valorização da moeda doméstica até 2011 foi acompanhada pela deterioração comercial de boa parte das atividades, excluindo a fabricação de papel e máquinas para trabalhar metal. Por outro lado, a valorização cambial piora a balança comercial referente à veículos de transporte de pessoas e peças e acessórios para veículos, sinalizando vazamento da demanda interna via importação do setor automotivo.

Durante o período da série analisada a política cambial foi marcada pela manutenção da moeda valorizada através da política de paridade cambial entre 1994 e 1999 e seguida por intensa desvalorização após mudança para o regime flutuante entre 1999 e 2004. Na segunda década, a apreciação da moeda doméstica via flutuação "suja" do câmbio até 2011, reacenderia o debate em torno do papel da taxa de câmbio na industrialização e no crescimento da produtividade. Por fim, o setor industrial brasileiro conviveu com diversas políticas industriais que tiveram sua efetividade pouco comprovada em meio às distorções macroeconômicas. Todavia, o setor de manufaturas de média tecnologia apresentou melhora em sua inserção externa durante o período de desvalorização cambial. Entretanto, com a contínua valorização da moeda doméstica, todos os setores passaram a piorar seu saldo comercial, inclusive o de manufaturas intensivas em recursos naturais e mão de obra. 
Gráfico 4 - Saldo comercial das manufaturas de média tecnologia e a taxa de câmbio efetiva real no Brasil entre 1995 e 2014

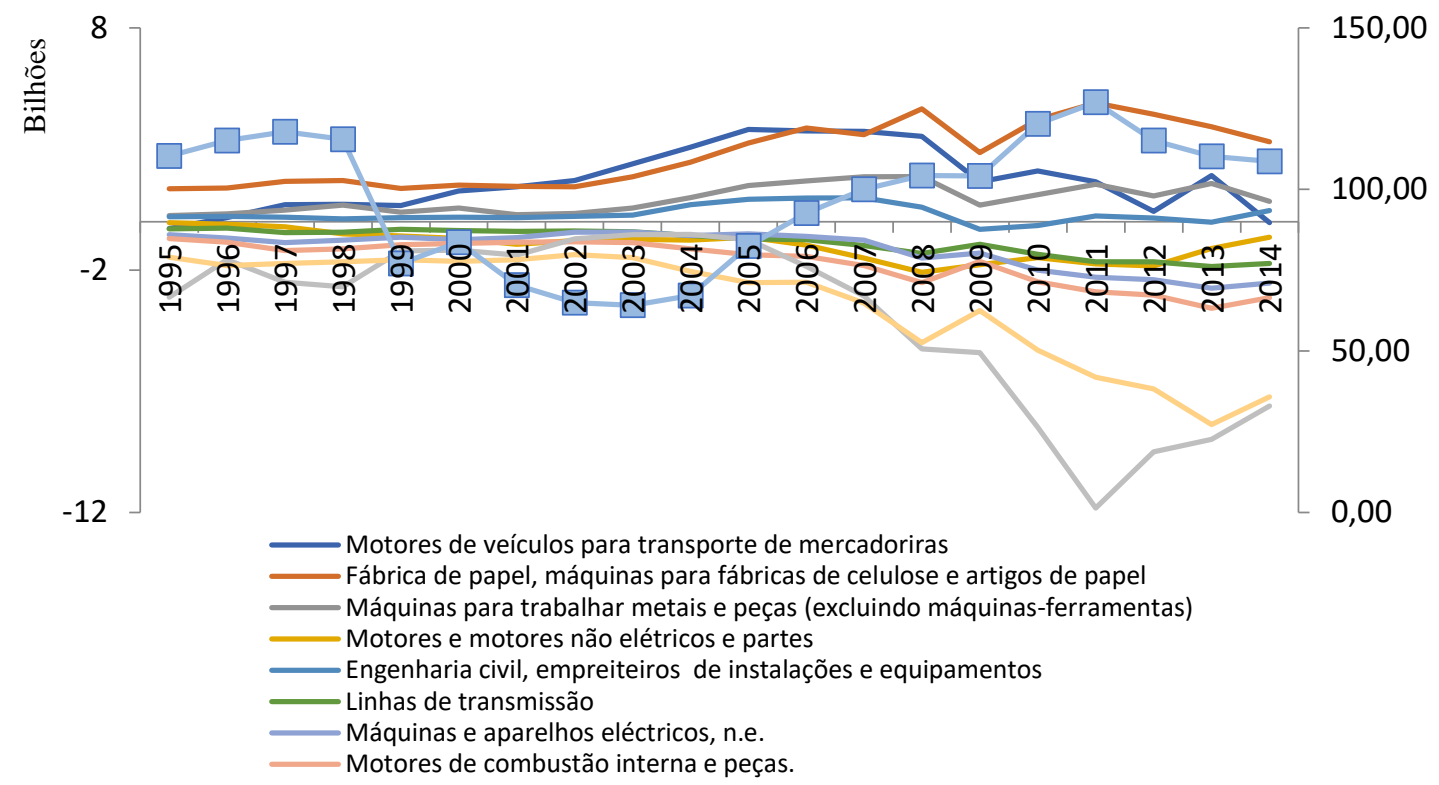

FONTE: IBRAHIM (2019) com base em UNCTAD-STAT e BRUEGEL

Para analisar, especificamente, a estrutura produtiva e tecnológica da indústria de Santa Catarina, são plotados no Gráfico 6 a participação da indústria de transformação no PIB de Santa Catarina e a balança comercial das manufaturas conforme intensidade tecnológica entre o período de 1997 e 2017. O processo de desindustrialização também se verifica na economia do estado, uma vez que a participação das manufaturas no PIB sai de 29\% em 2001para menos que $20 \%$ em 2016. Contudo, em meio a esse processo o setor de média e intensivo em trabalho e recursos naturais conseguiu melhorar, mesmo que temporariamente, sua inserção internacional. Todavia, a tendência a perda de competitividade da indústria nacional impacta no comércio internacional de todos os setores, chegando ao ponto de todo serem deficitário no final da série.

Mais especificamente, sobre as manufaturas de média intensidade tecnológica, os números das exportações desse setor do estado de Santa Catarina, ajudam a discriminar aqueles que contribuíram mais para a melhora inserção externa da indústria catarinense entre o período de 1997 e 2020. No Gráfico 7 são apresentados os a trajetória das exportações das 10 atividades manufatureiras de média intensidade tecnológica que mais contribuíram para o resultado do setor, elas representam $84 \%$ do total exportado em 2020. Apesar da pequena variação na grande maioria das atividades, vale destacar as que apresentaram melhores resultados ao longo da série: geradores elétricos giratórios e suas partes; bombas, centrífugas, compressores de ar, exaustores, aparelhos de filtrar ou depurar e suas partes; motores de pistão e suas partes; e, partes e acessórios dos veículos automotivos. Especificamente, são esses os setores que 
demonstraram alguma competitividade internacional ao longo de períodos específicos na nossa história econômica recente.

Gráfico 5 - Participação da indústria de transformação no PIB de Santa Catarina a preços constantes de $2010(\%)$ e a balança comercial das manufaturas conforme intensidade tecnológica entre 1997 e 2017 (R\$).

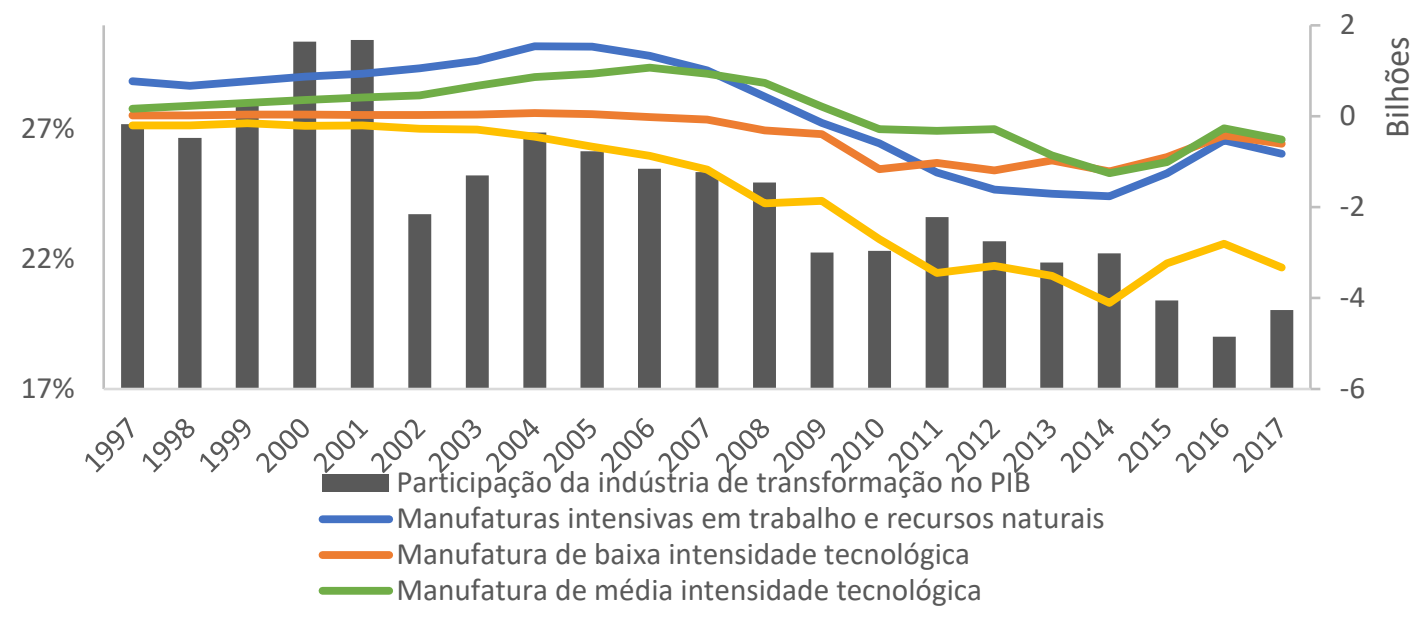

FONTE: IPEADATA

Gráfico 6 - Exportação das 10 principais atividades do setor de média intensidade tecnológica da indústria catarinense entre 1997 e 2020.

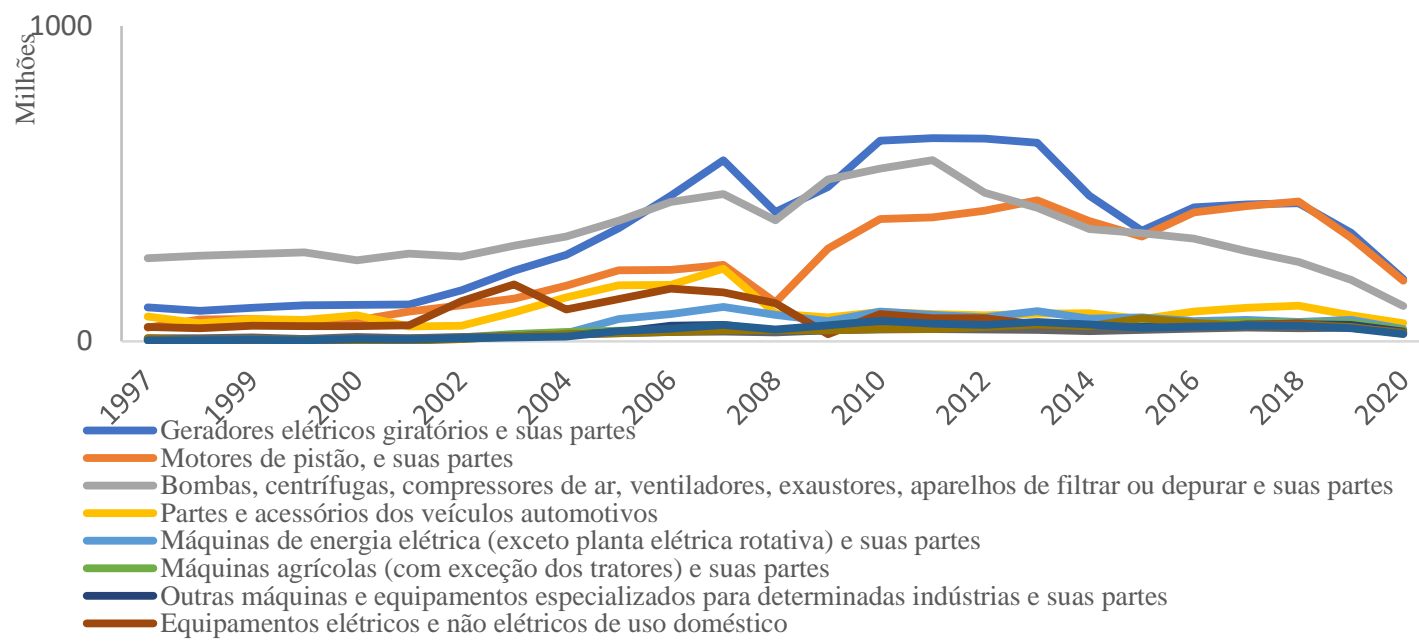

FONTE: IPEADATA

Por fim, os números de importação dos setores de média intensidade tecnológica permite comparar os produtos exportados pelo setor. Os setores plotados no Gráfico 7 representam cerca de $65 \%$ do total de importações do setor de média intensidade tecnológica, sendo as principais manufaturas importadas: veículos automóveis de passageiro; equipamentos elétricos e não elétricos de uso domésticos; máquinas e aparelhos elétricos; partes e acessórios de veículos automotivos. Em sua maioria, bens de consumo duráveis destinados à demanda interna e não à cadeia de produção e reexportação. 
A influência do processo de industrialização no crescimento e desenvolvimento das economias periféricas do sistema capitalista é um dos objetos de maior análise da escola estruturalista latino-americano. Em meio às mudanças na condução das políticas econômicas durante os anos de 1990, 2000 e 2010, o processo de industrialização das décadas anteriores foi revertido em direção a uma crescente desindustrialização da economia brasileira e catarinense. A perda de participação da indústria no PIB foi também acompanhada de uma piora significativa no saldo comercial, especialmente nos setores de maior intensidade tecnológica. Contudo, o setor de média intensidade tecnológica experimentou uma melhor inserção no mercado internacional na primeira metade da década de 2000.

Gráfico 7 - Importação das 10 principais atividades do setor de média intensidade tecnológica da indústria catarinense entre 1997 e 2021 (R\$).

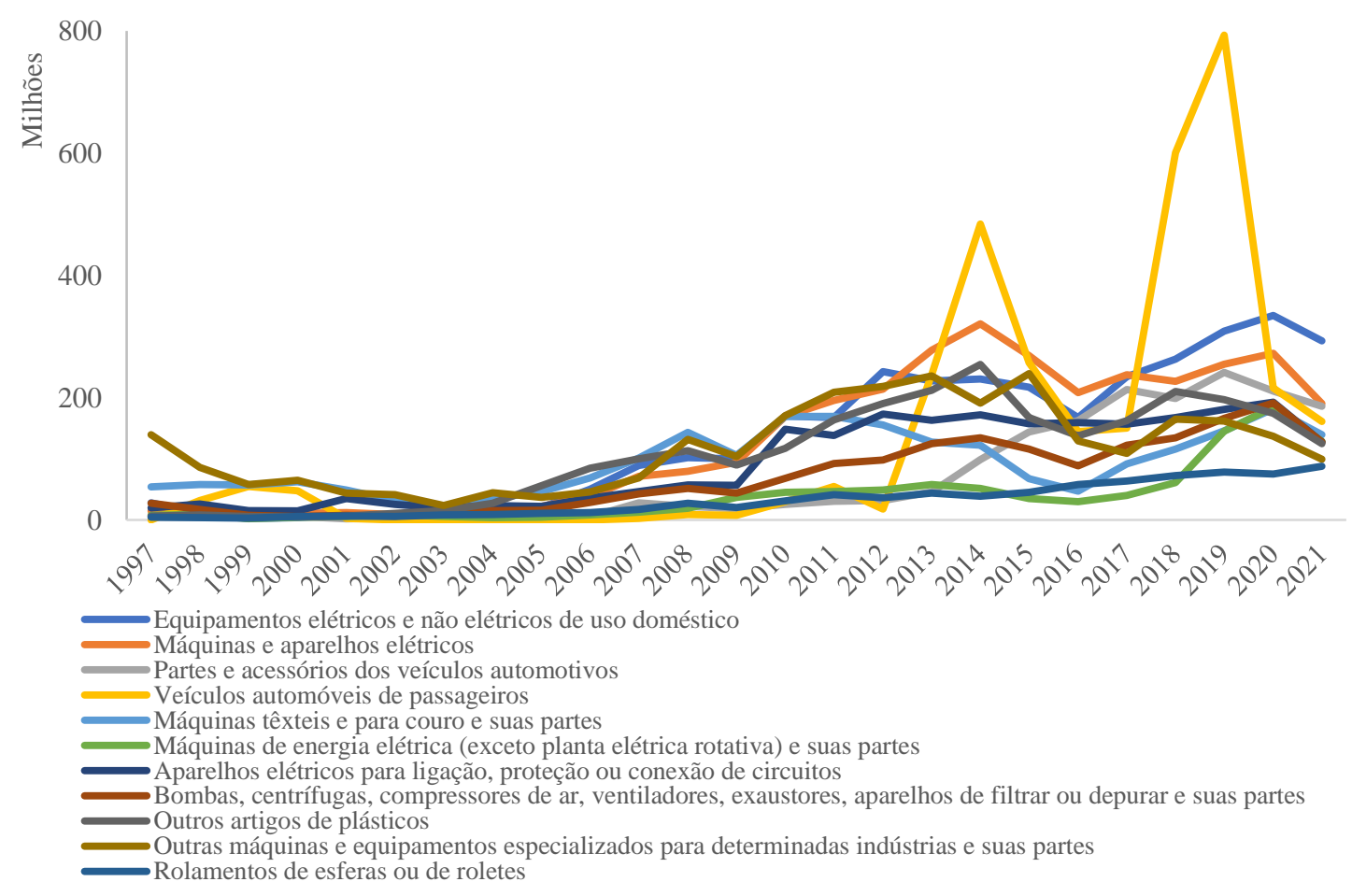

FONTE: IPEADATA

No Brasil se destacaram os setores de motores para veículos de transporte de mercadorias (caminhões e utilitários), de fabricação de papel, de maquinas de trabalho do metal e engenharia civil. Já, especificamente, para Santa Catarina, os mais expressivos foram os setores de geradores elétricos giratórios e suas partes; bombas, centrífugas, compressores de ar, exaustores, aparelhos de filtrar ou depurar e suas partes; motores de pistão e suas partes; e, partes e acessórios dos veículos automotivos que mostraram melhor competitividade, também nos anos 2000. Dessa forma, as atividades relacionadas com essas indústrias se mostraram como potenciais alvo de políticas industriais, que visem melhorar a inserção internacional da 
indústria brasileira e catarinense e, consequentemente, propiciar a retomada e sustentabilidade do processo de reindustrialização da economia brasileira.

\section{Conclusão}

$\mathrm{Na}$ estratégia de desenvolvimento econômico cepalina, o incentivo ao aumento da participação dos setores mais intensivos em tecnologia promove o crescimento dos retornos e das externalidades. Além disso, tais setores promovem as exportações, a acumulação de capital e, por fim, o crescimento sustentável. No caso da América Latina, acumulação de capacidades tecnológicas é constantemente afetada pela macroeconomia, através dos choques estruturais e por fracas instituições de ciência e tecnologia. Dessa forma, as estruturas produtivas da América Latina são resultadas da rápida liberalização do comércio, da apreciação da moeda nacional e de grandes fluxos de capital estrangeiro, bem como a ausência de políticas industriais e tecnológicas ativas, impactando nas estratégias competitivas das firmas.

De forma geral, a orientação cepalina mais tradicional é a promoção da atividade industrial para estágios de desenvolvimento superiores aos preexistentes. Com esse objetivo, a política industrial enfatiza o bem-estar da nação com um todo, não apenas o desenvolvimento específico e estéril de um setor industrial, mas uma coordenação das atividades industriais que mitigue perdas econômicas provenientes dos condicionantes específicos da periferia. Sendo a inovação a variável chave para o crescimento capitalista, o subdesenvolvimento é resultado da hierarquia tecnológica e da qualidade das instituições dedicadas a atividades científicas e tecnológicas localizadas no espaço nacional e sua capacidade de gerar e de se apropriar de paradigmas tecnológicos.

O desenvolvimento de um sistema nacional de inovação (SNI), com regras formais e informais, canaliza esforços de agentes heterogêneos, e é essencial para a acumulação de capacidades tecnológicas (CTs). Primeiramente, em nível micro, o aprendizado, os esforços para incorporar a inovação, reformar a organização e o processo de produção, adotar novas rotinas e desenvolver o conhecimento tácito, estão no cerne do crescimento da produtividade empresarial. Em segundo lugar, no nível macro, a estrutura produtiva alimenta retornos crescentes através da complementaridade entre setores e diferentes tipos de agentes (firmas e universidades); possibilita encadeamentos de conhecimento; e obtenção de externalidades positivas.

A partir desse arcabouço teórico, o presente trabalho investigou o perfil da indústria brasileira, sua contribuição para o PIB e sua inserção internacional através do saldo da balança 
comercial dos setores manufatureiros discriminados conforme sua intensidade tecnológica. Os resultados apresentados corroboram com a discussão central da teoria estruturalista sobre as dificuldades da industrialização nos países periféricos, principalmente quando se trata de competitividade industrial internacional nos setores mais tecnológicos. O resgate sobre a condução da política industrial brasileira na década de 1990 e 2000 mostrou que, além de plano tímidos e pouco efetivos, a política industrial não foi articulada m conformidade com as demais variáveis macroeconômicas e suas respectivas políticas econômicas. Contudo, alguns setores se mostraram competitivos em alguns momentos da história recente da economia brasileira e catarinense. Se o objetivo das políticas econômicas é aumentar a produtividade via aprofundamento da industrialização em setores de maior coeficiente tecnológico, os setores de média intensidade tecnológica se mostraram capazes de concorrer no mercado internacional dentro de certos cenários, e podem ser alvos de políticas industriais setoriais em consonância com as demais políticas econômicas (fiscal, cambial e monetária).

\section{Referências}

BIELSCHOWSKY, R. Cinquenta anos do pensamento na CEPAL - Uma resenha. In: BIELSCHOWSKY, R. (org.) Cinquenta anos do pensamento na CEPAL. Vol. 1, Rio de Janeiro: Record. 2000.

BLANKEnBurG, S.; PALMA, J. G.; TREgEnNA, F. Structuralism. The New Palgrave Dictionary of Economics. Second Edition. Edited by. Steven N. Durlauf and Lawrence E. Blume. Palgrave Macmillan, 2008. The New Palgrave Dictionary of Economics Online. 2010.

BRESSER-PEREIRA, L. C. Teoria novo-desenvolvimentista: uma síntese. Cadernos do Desenvolvimento, Rio de Janeiro, v. 11, n. 19, pp.145-165, jul.-dez. 2016.

COMISSÃO ECONÔMICA PARA AMÉRICA LATINA E CARIBE - CEPAL. Políticas de ajuste e renegociação da dívida externa na américa latina. In: Cuadernos de la Cepal. $\mathrm{N}^{\circ} 48$. Nações Unidas, $n^{\circ}$ de venda: S.84.II.G .18. Santiago do Chile, dezembro de 1985.

COMISSÃO ECONÔMICA PARA AMÉRICA LATINA E CARIBE - CEPAL. Transformación productiva con equidad. Série Libros de la Cepal, n 25 (LC/G.1601-P.). Santiago do Chile, março. Publicação das Nações Unidas, ${ }^{\circ}{ }^{\circ}$ de venda: S.90.II.G.6. 1990

CIMOLI, M; PORCILE, G. Learning, technological capabilities, and structural dynamics. In: OCAMPO, J; ROS, J (eds.). The Oxford Handbook of Latin American Economics. Oxford: Oxford University Press, 2011.

CIMOLI, M; PORCILE, G. Tecnología, heterogeneidad y crecimiento: un caja de herramientas estructuralista. Serie Desarrollo Productivo N 194. Cepal, Set. 2013. 
CIMOLI, M; PORCILE, G. Technology, structural change and BOP-constrained growth: a structuralist toolbox. Cambridge Economic Journal, v. 38, p. 215-237, 2014.

DOSI, G. Sources, Procedures, and microeconomic effects of innovation. Journal of Economic Literature, 26(3):1120-1171, 1988.

DOSI, G. Technological paradigms and technological trajectories. Revista Brasileira de Inovação, 5 (1): 17-32. 2008.

IBRAHIM, H. C. Políticas econômicas e as estratégias desenvolvimentistas no Século XXI. 2019. 426f. Tese (Doutorado em Economia) - Programa de Pós-graduação em Economia, Universidade Federal do Rio Grande do Sul, Porto Alegre. 2019.

KALDOR, N. Marginal productivity and the macroeconomic theories of distribution: comment on Samuelson and Modigliani, The Review of Economics Estudies, vol (33) pp. 309-19. 1966

LAMONICA, M. T.; FEIJÓ, C. A. Crescimento e industrialização no Brasil: uma interpretação à luz das propostas de Kaldor. Revista de Economia Política, vol. 31, nº 1 (121), pp. 118-138 janeiro-março. 2011.

MARCONI, N.; ROCHA, M. Taxa de câmbio, comércio exterior e desindustrialização precoce - o caso brasileiro. Economia e Sociedade, Campinas, v. 21, Número Especial, p. 853-888, dez. 2012.

MISSIO, F. J.; JAYME JR., F. G.; OREIRO, J. L. The structuralist tradition in economics: methodological and macroeconomics aspects. Revista de Economia Política, v. 34, p. 247266, 2015.

OCAMPO, J. The quest for dynamic efficiency: structural dynamics and economic growth in developing countries. In: OCAMPO, J. (ed.). Beyond reforms: structural dynamics and macroeconomic vulnerability. Stanford University Press, 2005

OREIRO, J. L.; FEIJO, C. A. Desindustrialização: conceituação, causas, efeitos e o caso brasileiro. Revista de Economia Política. São Paulo, v. 30, n. 2, p. 219-232, June 2010

PEREIRA, W.; CARIO, S. A. F. Indústria, desenvolvimento econômico e desindustrialização: sistematizando o debate no Brasil. Economia e desenvolvimento, Santa Maria, v. 29, p. 587, 2017

PEREZ, C. Cambio Técnico, Restructuration competitiva y reforma institucional enlos Países en Desarollo. El Trimestre Económico, v.61, 1992.

PEREZ, C. Revoluciones tecnológicas y capital financiero: la dinámica de las grandes burbujas financieras y las épocas de bonanza. México: Siglo XXI, 2004

PEREZ, C. Technological revolutions and techno-economic paradigms. Cambridge Journal of Economics, Vol. 34, No.1, pp. 185-202. 2010.

PREBISCH, R. El desarrollo económico de América Latina y sus principales problemas (E/CN.12/89), Santiago do Chile, Cepal , 1949. 
RODRIGUEZ, O. O estruturalismo latino-americano. Rio de Janeiro: Civilização Brasileira, 2009.

RIBEIRO, R.; MCCOMBIE, J.; LIMA, G. Does real exchange rate undervaluation really promote economic growth?. Structural Change and Economic Dynamics, Elsevier, vol. 52(C), pages 408-417 2020.

THIRLWALL, A. P. The balance of payments constraint as a explanation of international growth rate differences. Banca Nazionale del Lavoro Quarterly Review, 128, 1980. 